\title{
Russian research may be put on lean diet
}

\begin{abstract}
Moscow. Russia can no longer support its scientific community in the style to which it was once accustomed, according to Boris Saltykov, the science minister. And a new study suggests that the government is uncertain about whether to spend enough to maintain a first-class research enterprise.

Late last month, Saltykov presented to the Russian cabinet a proposal for a 'new science policy' that abandons support for across-the-board basic research and replaces it with an emphasis on priority projects. Moreover, the government will itself decide what those projects are. The leadership seems to have found the scheme attractive enough to appoint Saltykov deputy prime minister.

Under the new arrangements, there will be a stringent procedure for identifying which research institutions should retain their current privileges, including tax concessions and low rent. In future, funding for institutions will be replaced by funding for individuals, whose financial independence will be encouraged.
\end{abstract}

Saltykov's position is that Russia does not have the funds to satisfy everybody. Nor should it try, he says, for the future structure of the scientific community, the management of science and the mechanisms of funding will be very different from what they are now. The new science policy will be implemented by two official bodies working in tandem: the Ministry of Science and the newly instituted Staff Office for Science and Technology Policies, the function of which is vaguely defined as "preparing and monitoring cabinet decisions".

This arrangement is by no means the loose and ineffectual organization it may seem. Saltykov and the head of the staff office, Ilya Lomakin-Rumyantsev, were successively the coordinators of a major study, under the aegis of the Russian Academy of Sciences, to analyse the status of research in Russia and to make recommendations.

Lack of money is not the only explanation for the stringency of the new policy. Lomakin-Rumyantsev says that the government is seeking deliberately to break away from the traditional organization of research under central authority. And while it is conscious of the hardships many scientists will encounter, it believes its new stringency will "encourage researchers to look for solutions on their own".

Lomakin-Rumyantsev says that there are three immediate tasks to tackle: to increase funding, not necessarily from the public sector, to change the mechanism by which that funding is disbursed and to "create a solid and innovative legal framework for building a new model of science, largely based on nongovernment funds and deeply immersed in the production sphere".

The study on which Saltykov and Lomakin-Rumyantsev have been engaged has evidently taken a cold look at the international status of the new Russia. It says that Russia is now at a "bifurcation point" and that its choices will determine its scientific future. If Russia retains a position of leadership, the study argues, it will need an appropriately advanced scientific community. But if it emerges as a second-rate power, it will have to be content with a derivative research establishment to support production in high technology. The worst case, according to the study, is that Russia will join the Third World' and thus require no scientific establishment at all.

Although predictions are impossible, most analysts in Moscow believe that the compass needle is fluctuating between the second and third positions. But the adoption of new science policy suggests some optimism within the government about the future. "If we wanted to proceed along the third path", say Lomakin-Rumyantsev, "we would need no special policy at all."

Vladimir Pokrovsky

\section{Debate over animals is given a personal touch}

Washington. Sending thank-you cards to researchers across the United States from parents whose children are living because of medical interventions that were tested on animals is the latest wrinkle in a broad national campaign to win over the US public in a battle against those who oppose the use of animals in research.

Norma Myers Rumpf, with her healthy three-year-old son Lee asleep on her shoul-

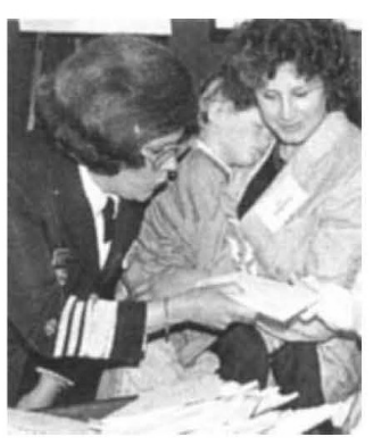

Rumpf delivers cards to Surgeon General Novello. der, spoke last week at a rally at the US Capitol about her volunteer effort to reassure scientists facing protests from animal-rights activists that their work is worthwhile. She received a standing ovation from representatives of a coalition of 250 organizations universities, professional societies, patient support groups, health care companies, vol- unteer health associations and individual researchers and physicians - formed six months ago to convey the message, as proclaimed on buttons and T-shirts, that "animal research saves lives". Rumpf presented Antonio Novello, the US Surgeon General, with 467 thank-you cards from the parents of children who, along with her newborn son, were saved from respiratory failure by the use of extra corporeal membrane oxygenation (ECMO), a procedure refined on sheep before it was applied to humans.

"Two out of three young people question the use of animals in research", said Frederick Goodwin, director of the National Institute of Mental Health, in reporting the results of a recent national poll on public support for biomedical research. "That tells you how much work we have to do in conducting an educational program on the value of research involving animals."

Although Goodwin says that he is confident "we will prevail in the long run", the rally reflected the concern among the biomedical community about the visibility and continued strength of the animal rights movement. "The 1980s was a lost decade for us", says Adrian Morrison, a veterinary researcher at the University of Pennsylvania who has been a target of protesters and a leader in the effort to marshal public support. "It took scientists a long time to get organized, but I think that we've turned the corner."

For Rumpf, the turning point came two years ago when she read about a protest at the US National Institutes of Health (NIH) staged by People for the Ethical Treatment of Animals (PETA). "I thought about how hard it must be for a scientist to get up and go to work, knowing that people will be screaming in his face as he drives into his lab." The next day Rumpf wrote a letter of support to the $\mathrm{NIH}$, and last year she presented more than 100 letters from thankful parents to Bernadine Healy, the director of NIH.

Rumpf, who works from her home in Arlington, Virginia, collects the letters and snapshots from grateful parents and sends them to scientists identified by various reseach organizations as working with animals. Her goal is to mail a thank-you card to every laboratory in the country, although she admits candidly that she does not know how long she can continue. Still, she seems willing to lick stamps for a while longer.

"There's nothing that I can do to repay them" for saving her child's life, she says. "The least I can do is pat them on the back and tell them to keep up the good work."

Jeffrey Mervis 